hydrophobia-due to the preventive treatment-has occurred amongst the 7000 persons who have so far undergone the cure.

Now let me put before you the answer to the question, Is this treatment a real cure? For this has been doubted by persons, some of whom will I fear still cloubt or profess to doubt, and still abuse Pasteur whatever is said or done! From all that can be learnt about the matter, it appears pretty certain that about from fifteen to twenty persons out of every hundred bitten by mad dogs or cats, and not treated by Pasteur's method, develop the disease, for I need scarcely add that all other methods of treatment have proved fallacious; but bites on the face are much more dangerous, the proportion of fatal cases reaching 80 per cent. Now of 2164 persons treated in the Pasteur Institute, from November I 885 to January I 887 , only thirty-two died, showing a mortality of 14 per cent. instead of fifteen to twenty, and amongst these upwards of 2000 persons, 2 I 4 had been bitten on the face, a class of wounds in which, as I have said, when untreated, the mortality is very high; so that the reduclion in the death-rate seems more remarkable, especially when we learn that in all these cases the animal inflicting the wound had been proved to be rabid. The same thing cccurs even in a more marked degree in 1887 and 1888 . In 1887,1778 cases were treated, with a mortality of $\mathrm{I} \cdot 3$ per cent., whilst last year $\mathrm{I} 626$ cases were treated, with a mortality of $\mathrm{I} \cdot \mathrm{I} 6$ per cent.

Statistics of the anti.rabic treatment in other countries show similar results, proving beyond a doubt that the death-rate from hydrophobia is greatly reduced. Indeed, it may truly be said that in no case of dangerous disease, treated either by medicine or surgery, is a cure so probable. Moreover, in spite of assertions to the contrary, no proof can be given that in any single case did death arise from the treatment itself. And as showing the safety of the inoculation, I may add that all Pasteur's assistants and laboratory workers have undergone the treatment, and no case of hydrophobia has occurred amongst them.

You are no doubt aware that Pasteur's anti-rabic treatment has been strongly opposed by certain persons, some of whom have not scrupled to descend to personal abuse of a virulent character of those who in any way encouraged or supported Pasteur's views, and all of whom persistently deny that anything good has come or can come from investigations of the kind. Such persons we need neither fear nor hate. Their opposition is as powerless to arrest the march of science as was King Canute's order to stop the rising tide. Only let us rest upon the sure basis of exactly ascertained fact, and we may safely defy alike the vapourings of the sentimentalist and the wrath of the opponent of scientific progress. But opposition of a much fairer character has likewise to be met, and it has with propriety been asked---How comes it that Pasteur is not uniformly successful? Why, if what you tell us is true, do any deaths at all follow the anti-rabic treatment? The answer is not far to seek. In the first place, just as it is not every vaccination which protects against small pox, so Pasteur's vaccination against rabies occasionally fails. 'Then, again, Pasteur's treatment is really a race between a strong and an attenuated virus. In cases in which the bite occurs near a nervi-centre, the fatal malady may outstrip the trea ment in this race between lire and death. If the weakened virus can ast in time, it means life. If the strong virus acts first, prevention comes too late-it means death. So that the treatment is not doubtful in all cases, but only doubtful in those which are under well-known unfavourable conditions. This, it seems to me, is a compl ste reply to those who ignorantly fancy that, because Pasteur's trealment has not cured every case, it must be unreliable and worthless.

One word more. I have said that Pasteur is still-as he has always been--a chemist. How does this tit in with the fact that his recent researches seem to be entirely of a biological character ? This is true. They seem, but they really are not. Let me in a few sentences explain what I mean. You know that yeast produces a peculiar chemical substance-alcohol. How it does so we cannot yet explain, but the fact remains. Gradually, through Pasteur's researches, we are coming to understand that this is not an isolated case, but that the growth of every micro-organism is productive of some special chemical substance, and that the true pathogenic virus-or the poison causing the disease--is not the microbe itself, but the chemical compound which its growth creates. Here cnce more "to the solid ground of nature trusts the man that builds for aye," and it is only by experiment that these things can be learnt.

For further details, sse Dr. Ruffir, Brit. Met. Journ., Sept. 2r, 1889 .
Let me illustrate this by the most recent and perhaps the most striking example we know of. The disease of djphtheria is accompanied by a peculiar microbe, which, however, only grows outside, as it were, of the body, but death often takes place with frightful rapidity. This takes place not by any action of the microbe itself, but by simple foisoning due to the products of the growing organism, which penetrate into the system, although the microbe does not. This diphtheritic Bacillus can be cultivated, and the chemical poison which it produces can be completely separated by filtration from the microbe itself, just as alcohol can be separated from the yeast granules. If this be done, and one drop of this pellucid liquid given to an animal, that animal dies with all the well-known symptoms of the disease. This, and similar experiments made with the microbes of other diseases, lead to the conclusion that in infectious maladies the cause of death is poisoning by a distinct chemical compound, the microbe being not only the means of spreading the infection, but also the manufacturer of the poison. But more than this, it has lately been proved that a small dose of these soluble chemical poisons confers immunity. If the poison be administered in such a manner as to avoid speedy poisoning, but so as gradually to accustom the animal to its presence, the creature becomes not only refractory to toxic doses of the poison, but also even to the microbe itself. So that instead of introducing the micro-organism itself into the body, it may now only be necessary to vaccinate with a chemical substance which in large doses brings about the disease, but in small ones confers immunity from it, reminding one of Hahnemann's dictum of "Similia similibus curantur:"

Here then we are once more on chemical ground. True, on ground which is full of unexplained wonders, which, however, depend on laws we are at least in part acquainted with, so that we may in good heart undertake their investigation, and look forward to the time when kncwledge will take the place of wonder.

In conclusion, I feel that :cme snrt of apology is needed in thus bringing a rather serious piece of business before you on this occasion. Still I hope for your forgiveness, as niy motive has teen to explain to you as clearly as I could the life-work of a chemist who has in my opinion conferred benefits as yet untold and perhaps unexampled on mankird, and I may be allowed to close my discourse with the noble words of our hero spoken at the cpening of the Pasteur Institute in the presence of the President of the French Republic :-

"Two adverse laws seem to me now in contest. One law of blood and death, opening out each day new modes of destruction, forces nations to be always ready for the battlefield. The other a law of peace, of work, of safety, whose only study is to deliver man from the calamities which beset him.

"The one seeks only violent conquests. The other only the relief of humanity. The one places a single life above all victories. The other sacrifices the lives of hundreds of thousands to the ambition of a single individual. The law of which we are the instruments, strives even through the carnage to cure the bloody wounds caused by this law of war. Treatment by our antiseptic methods may preserve thousands of soldiers.

"Which of these tuo laws will prevail over the other? God only hnows. But of this we may be sure, that science in obeying this law of humanity will always labour to enlarge the frontiers of life."

\section{THE PHYSICAL PAPERS AT THE BRITISH ASSCCIATION.}

PROF. A. W. RÜCKER, F.R.S., read a paper on cometic nebulæ. Prof. Lockyer has suggested that comtt-like nebulæ may be caused by the passage of a very dense swarm through a stream of meteorites, the relative velocity of the two being very considerable. The author has, therefore, attempted to calculate the increase in the number of collisions which takes place in the rear of an attracting mass which passes through a swarm of meteorites so sparsely scattered through space that the main effects of the attraction are produced in a distance which is small compared with the length of the mean free path. Assuming, with Clausius, that the particles have equal velocities equally distributed in all directions, and which are small compared with the relative velocity of approach, the collisions will be most numerous within a cone the apex of which is the attracting body or nucleus, and which contains the lines which are parallel to the relative velocities of the individual metecrites 
and the nucleus when at an infinite distanse apart. The collisions will increase exormously when the nebulæ. cэm the sun, and will take place about every second at points, in round numbars, ros miles apart.

Prof. C. Piazzi Smyth, late Astronomar-Royal for Sostland, read a papar entitled "Re-examination of the $\mathrm{S}_{\mathrm{p}}$ ectra of Twanty-three Gis-vacuum, Ent-on Tubes, after six to ten years of existence and use." This inquiry began in an attem $t^{t}$ to ascertain, by refined msnsurations, whether there was any sensible difference of spectral place for hydrogen lines, when they appeared a dventitiously and scantily in tubes of other and very different gases, or in tubas of nothing but pure and abundant hydrogen by original intention. Bat, after having obtained a negative in every case, the inquirer became more taken up with the changes that had occurred in certain of the tubes subsequent to 1880 , when he published upon them in the Trans actions of the Royal Sosiety of Edinburyh. Thus, a chlorine tube, of which it was printed in I880 that it was then stil showing its chlorine lines, though fainter, after two years' use while carbon bands and hydrogen lines had begun to appear yet now, in 1889 , it has nothing bat hydrogen lines, an 1 in greal brilliance, to show. Again, an iodine tube which had a comparatively large quantity of solid iodine granules introduced into, and sealed up in, its interior eleven years ago ; ant showe then a splendid spectrum of 148 measured iodine lines, extend ing discontinously from red to violet, an t had nothing else, s $x y$ ? three very faint puny imıges of the three principal lines of hydrogen-this tube, in $\mathbf{1} 839$, has not a single iodine line now left ; but its spectrum, which is brighter than ever, is com posed of nothing but hydrogen lines, so that the once solid iodine gran iles would seem to be partly changed into hydrozen, and partly deposited on the inside of the tube as yellow haze, beside leaving a trifle of loose dust. The author also mentions with much satisfaction that a London maker, Mr. Charles Casella, transcended all others by supplyins him with one tube of $\mathrm{CO}$, two of $N$, and two of $O$, which have, through six years of existeace and work, shown their respective spectra without a tracs of hydrozen.

Lord Rayleigh, Sac. R.S., in a papar on the tones of bells, said that observations were made on a considerable number of bells of the usual church pattern. Tae pitch of the variou; tone; usually five for each bill, was fixed by comoxrison with a har monium and with the aid of resonatorj. The nominal pitch of the bell; appear's to depsn 1 on the highest of the tone; recorded. From a musical point of view it would seem that all the bells are far removed from perfection; while the differeaces of relative pitch in the variou; cases recorded indicates that it may be possible to effect an improvement even to the extent of bringing all the five tones into harmonious relations. The quality of the sound is, however, very difficult to estimate, and even the imperfect octaves, of which several examples occur, give much less of a dissonant effect than might have been expected.

Captain Abney, F.R.S., read a paper on the quantity of deposit of silver produced by the development on a photographic plate in term; of the intensity of light acting. The author concludes from his experiments that the deposit of silver made by different intensities of light varies directly as the intensity of light acting-this, of course, within such limits that reversal of the image is not commenced, and that the film is not at any part exhausted of the silver salt which can be reduced.

Lord Kayleigh, Sec. R.S., read a paper on pin-hole photography. It was shown, in the Piilosopinical Mrgazine for 1880 , that a simple aperture was as effective as the best possible lens in forming an image, provided only that the focal length $(f)$ was sufficiently great. Conversely, if $f$ be given, the aperture may be made so sinall that the use of a lens will give no advantage ; but if the focal length was such as was usually afforded by a camera, the admissible aperture, being very much less than that of the pupil of the eye, is in ifficient for reasonably good definition. In some recent experiments the focal length was about 9 feet, and the aperture $\frac{1}{16}$ inch. The specimens exhibited were taken upon gelatine plates, an 1 represented a weathercock seen against the sky. The amount of detail was not $m$ iterially less than thit observable by direct vision in the case of ordinary eye; but modern plates are so sensitive that there would be no difficulty in working with an aperture equal to that of the papil, other than that incurred in poviding a focal lenrth of 65 feet, with the necessary exclusion of foreign light.

Prof. O. J. Lodge, F.R.S., and Mr. R. T. Glazebrook, F. R.S., read a paper on the determination of $v$ by means of electric oscillations. The authors have recently made a determination of $z$, using the oscillatory discharge of a condenser. The period of the discharge, which passed between two terminals connected through a circuit of measured self-induction to a condenser of known capacity, was determined by forming an image of the spark on the edge of a rapidly revolving circular photographic plate, the rate of revolution being accurately ascertained.

Prof. $\Lambda$. W. Rücker, F.R.S, read a paper on the instruments used in the recent magnetic survey of France. A magnetic survey of France has recently been completed by M. Moureaux, who has determined the magnetic elements at some seventy stations. Prof. Ruicker exhibited a set of instruments recently made under the supervision of M. Moureaux for the Science Museum at South Kensington. The point aimed at in their construction was to secure accuracy combined with dimensions and weight much less than those of the Kew pattern instruments. The main points in the construction are ( $\mathrm{I}$ ) that the needles used are much smaller than those used in the Kew pattern instriments ; (2) the end of the declination needle forms a concave mirror, and a reading is taken when the image of a linear mark formed by the mirror is in the prolongation of another line which is exactly opposite to the first on a thin piece of metal ; (3) the geographical meridian is determined by a theodolite, which forms part of the apparatus, instead of by using - as in the Kew -a plane mirror to reflect the image of the sun into a horizontal telescope ; (4) extremely fine silk threads are able to support the small magnets used; $(5)$ in the dip circle the graduated arc rotates in its own plane about a horizontal axis, and a reading is taken when the end of the needle and its image, formed by a concave mirror attached to the graduated circle, coincide when viewed through a microscope.

Prof. J. A. Ewing, F.R.S., in a paper on the magnetic viscosity of iron, described experiments showing that in certain circumstances the process is gradual by which iron assumes magnetization after the imposition of magnetizing force. The experiments are given in detail in Proc. Roy. Soc., June 20, 1889 .

Prof. Everett, F.R.S., read a paper on the relation between brachistochrones and ray-paths, in which he pointed out an application of well-known laws of optics to the comparison of the law of force for a free path with the law of force for a path of least time, the path itself being supposed given; and to the closely allied problems of deducing the form of the path of least time from the form of the free path when the law of force is given. Most of his results, he stated, have previously been ob. tained by means of the principle of least action, but the optical method will be available for many students who have not mastered that principle.

Prof. Cayley, F.R.S., addressed the Section on curves in space.

Prof. I. A. Ewing, F. R.S., read a paper on hysteresis in the relation of strain to stress. It is now well known that when an iron wire is subjected to the alternate application and removal of tensile stress, many times repeated, certain of. its qualities which are affected by the changes of stress exhibit hysteresis with regard to the changes of stress. If the load is cyclically varied between definite limits, these qualities do not have the same values at corresponding intermediate points during the application and removal of load; there is hysteresis or lagging in the change of quality, and in some cases this appears to be of a static character - that is to say, independent of the time-rate of variation of stress. Conspicuous instances of this action are seen in the change of magnetic and thermo-electric qualities under change of stress, some of which have been described by the author in former papers. It is natural to look for an effect of the same kind in the extension and retraction which the wire undergoes. We should expect that, after the change of loads has been frequently repeated so that a cyclic régince is established, the wire will, for any value of load intermediate between the two extremes, be longer during unloading than during loading. Evidently, if such an effect exist, it must be small, as it is well known that the proportionality of strain to stress which is expressed by Hooke's law is at least approximately exact. Sir W. Thomson's experiments on the damping of torsional vibrators have long ago shown that, an action of the kind spoken of occurs in quickly. performed cycles of torsional strain. But it does not appear to have been looked for in slow cycles of longitudinal pull. The author has, with the assistance of one of his students, Mr. D. Low, looked for the effect in question, and has found it, not only 
in iron, but in steel, brass, and copper wires. He has not yet examined other metals. The experiment consisted in observing, with much optical magnification, the extension of a very long piece of wire, directly loaded with lead weights. The wire was hung from a rigid support in a testing flue or recess, built in the wall of the laboratory, and extending up through four stories. At a distance of $806 \mathrm{cms}$. below the top a small clamp was fixed on the wire, and this formed the support of the back foot of a little tripod, the feet of which consisted of three needle points about an inch apart. The two front feet rested in a slot and hole in a fixed shelf which stood in front of the long wire. The tripod carried a plane mirror which became tilted forward or backward as the wire extended or retracted. Readings were taken by a telescope of the reflected scale of a levelling staff placed vertically at a distance of some 5 metres from the mirror. The staff was graduated to $1 / 100$ of a foot, and it was easy to read by estimation to $\mathrm{I} / \mathrm{I} 000$ of a foot, which corresponded to 0.000000102 of the length of the wire. At first a fixed shelf was used to support the two front feet of the mirror, but the effects of temperature were found to be excessive, although the greatest care was taken to shield the wire from draughts; and the plan was resorted to of hanging the shelf from two adjacent wires of the same material, suspended from the same support as the wire which was to be stretched. In this form the arrangement for optical multiplication was nearly the same as one used by $\mathrm{Mr}$. Bottomley in recent experiments on the exterision of loaded wires by heat.

Prof. Henry Stroud, in a paper on the E.M.F. produced by an abrupt variation of temperature at the point of contact of two portions of the same metal, gave the results of experiments on the E.M.F. produced when two portions of the same metal are in contact, and one portion is kept at a high temperature and the other at a low temperature. The precautions necessary in the performance of such experiments are discussed in the paper, and the results obtained are given in the case of copper and iron. The E.M.F. established in the case of copper is from hot to cold across the junction, while in the case of iron it is from cold to hot, and of far greater magnitude. These experiments are being continued with a view to obtaining the relation between the E.M.F. and the difference of temperature.

Prof. McLeod, F.R.S., in a paper on the black-bulk thermometer in vacuo, concludes the black bulbs should be as small as possible, and very little of the stem blackened, and also that the case should be as thin as is consistent with strength.

Sir W. Thomson, F.R.S., communicated a paper, by Magnus Maclean and Makita Goto, on electrification of air by combustion. A series of experiments was made, under the instructions of Sir William Thomson, for the purpose of endeavouring to find: (I) the state of the air inside a room as regards electrification; (2) the relation between electrification of air within a building and the atmospheric potential in its neighbourhood outside; and (3) the causes which produce or change the electrification of any given mass of air. It $w$ as found that an inclosed mass of air is electrified negatively by the burning of a paraffin lamp, of coal gas, of sulphur, of magnesium, and of several other substances; and, on the other hand, the burning of charcoal electrified a room positively.

Prof. C. Michie Smith read some notes on atmospheric electricity and the use of Sir W. Thomson's portable electrometer. Recent observations fully confirm the author's previous conclusions that, with a dry west wind, the potential of the air for some distance above the ground is usually negative. This seems always to be associated with dusty air. In using the portable electrometer in hot moist climates, special precautions have to be taken in drying it. As much sulphuric acid must be used as the pumice can absorb, and the pumice should be dried at least once a fortnight. The charging-rod itself must be very carefully dried, and, after charging, should be lifted out with a piece of warm silk.

Mr. A. W. Clayden read a paper on dark flashes of lightning. The author exhibited a negative taken on June 6 last, which shows several reversed images of lightning-flashes. He described a series of experiments which he had carried out with the object of discovering whether the phenomenon could be imitated in the laboratory. The steps in the investigation were illustrated by a series of negatives showing photographs of electric sparks. The conclusions arrived at are, that photographic images of electric sparks can be reversed by the action of diffused light. Reversal is only produced when the exposure to diffused light is subsequent to (or possibly simultaneous with) exposure to the image of the spark. If the plate is first acted upon by diffused light, the sparks give a direct image unless the action has been considerable, in which case they seem to make no impression.

Prof. Cleveland Abhe, in a paper on the determination of the amount of rainfall, gave a résumé of the general results of investigations on this subject. The deficit in catch by a gauge due to the eddies of wind is shown, on general reasoning, to be proportional to the velocity of the wind and to the relative percentage of small and slowly-falling drops.

Prof. C. Piazzi Smyth, late Astronomer-Royal for Scotland, read a paper entitled "IHygrometry in the Meteorological Four. nal." After noting the superior value officially attached to determinations of the mean temperature by observations of self-registering thermometers, recording its maximum and minimum every twenty-four hours, the author inquires why the still more difficult problem of ascertaining the mean daily moisture of the atmosphere is thrown over to a different principle of observing, long since condemned for simple temperature. Believing that the want of good self-registering dry-and wet-bulb thermometers for the purpose was the chief obstacle, and having alighted on some recent makes of Sixe's thermometers with several very recommendable qualities, he invested two out of four of them with the peculiar fittings for wet-bulb hygrometers, after having made a table of index corrections for them all, as compared with standard thermometers. But as soon as hygrometric observations began, the depression of the wet, below the dry, bulb always came out at only two-thirds of what a standard but non-registering Glaisher arrangement gave out, for the horizontal form of Sixe, and no more than half for a vertical form. These differences of hygrometric statement, though rather puzzling for a time, were traced up to the wet bulbs of the Sixe's thermometers being in contact on one side with the scale-plate. For when that plate in the horizontal Sixe form was cut entirely away from the bulb, and a new vertical form of Sixe was made (fer Mr. James Bryson, Edinburgh) with its long thin bulb wholly outside the rest of the instrument, the indications of all three varieties of wet-tulb hygrometers became practically the same; and hygrometry was relieved of the old drawback on its registrations of maximum and minimum quantities of moisture in every twenty four hours.

Mr. F. T. Trouton read a paper on some experiments on radiation with Prof. Hertz's mirrors. These experiments were described in Naturf, vol. xxxix. p. 39I, and vol. xl. p. 398. Certain of them were repeated by Mr. Trouton in the Physical Laboratory of the Durlam College of Science.

Profs. A. W. Ruicker, F.R.S., and T. E. Thorpe, F.R.S., read a paper, on the relation between the geological constitution and the magnetic state of the United Kingdom, before a joint meeting of Sections $A$ and $C$. The authors have, during the last five summers, determined the magnetic elements at 200 stations, distributed over the whole of the United Kingdom, and have employed the results of their observations in a study of the disturbing magnetic forces in play in various districts. If all disturbing causes were removed, an observer travelling due west from London would find that the declination increased by about half a degree for each clegree of longitude. In fact, the rate of increase, though equal on an average to this amount, is irregular. Between London and Windsor it is considerably larger, and between Windsor and Reading smaller than the mean. The forces which produce these abnormal variations depend upon the geological character of the district. Two principal theories have been proposed to account for these disturbances : (I) the theory of direct action of magnetic rocks; (2) the other explanation associates the deflection of the needle with disturbances of the earth currents of electricity produced by irregularities in the geological constitntion of the country, and especially with geological faults. On the whole, the authors think that the theory of the direct action of magnetic rocks agrees best with the o'served facts, and they have shown that the kingdom can be divided into a small number of magnetic districts in which the directions of the disturbing forces are evidently closely connected with the geological constitution.

In a paper on the passage of electricity through gases, Prof. Arthur Schuster, F.R.S., gave an acccount of his investigations during the last two years on the distribution of potential in the neightourhood of the negative pole of discharge of electricity through rarefied gases. Knowing the rate of fall of potential, it can be determined whether there is any bodily electrification in any part of the negative glow. It was found that the kathode is, 
surrounde $l$ by an atmosphere of positively electrified gaseous particles extending to the outer edge of the so-called dark space. According to the author's views, this atmosphere corresponds to the polarized layer adjoining the negative electrode in an electrolyte. The cause of the sudden difference in luminosity between the dark space and the negative glow has also been investigated, and it has been found that negative particles projected from the kathode pass unhindered through the dark space, while their velocity is quickly reduced in the glow proper, the translatory energy being thus changed into energy of vibration.

Prof. Oliver J. Lodge, F.R.S., read a paper on the failure of metal sheets to screen off the electrostatic effect of moving or varying charges. Experiments have been made on the screening effect of a very thin film of silver chemically deposited, the thickness of the deposit being different in the different experiments. The silver screens are only found to protect so long as they are opaque; they no longer do so when the deposit is so thin as to be transparent.

Prof. James Blyth described a new form of current-weigher. In the construction of balances for the measurement of electric currents, a greater or less difficulty has always been experienced in leading the current into the movable parts of the instrument without seriously interfering with its sensibility. Several methods have been adopted to overcome this difficulty. In some balances the current is led in by mercury cups; in others, flexibie leads, made of thin wire spirals or thin metal strips, are employed; while, in the recent balances by Sir William Thomson, the difficulty has been overcome by means of his well-known ligature suspension. Some time ago it occurred to the author that still another form of balance might be enployed for this purpose, and the present paper is a short description of one which he has made. The balance referred to is of the ordinary Roberval type, with the pivot connections all replaced by tightly-stretched torsion wires. It is constructed as follows:-On a flat baseboard are placed two vertical uprights of wood or other insulating material, about 6 inches apart. Between these are stretched two parallel wires in the same vertical plane about 3 inches apart. To the middle points of these wire; are soldered the two horizontal metal bars of the Roberval. These are about 9 inches long. Buth horizontal bars terminate at each end eith 2 in forks or rings, placed in a horizontal plane, and wires are tightly stretched between the prongs of the forks, or across a diamster of the rings. To the middle points of these last wires are attached, also by soldering, the vertical bars of the bzlance, thus completing what takes the place of the ordinary jointed parallelogram of the Roberval. The vertical bars have matal terminals, insulated from each other, and carry the circular disks, on the rim; of which the movable coils of wire are wound. The bars pass at right angles through the centres of the disks, and are fixed to them at their middle points. The middle coils, which are of exactly the same diameter as the movable ones, are supported from the base-board, and are placed so that one is about half an inch above one movable coil, while the other is as much below the other movable coil. From this it will be seen that, when the balance is in equilibrium, the fixed and movable coils are all horizontal, with a space of about half an inch between each pair. The stretched wires may be either of steel or phosphor-bronze, and before being finally soldered are placed under considerable tension. The carrent flows through the instrument thus :-Entering, say, by the upper wire connecting the fixed supports, it passes to the upper horizontal bar. There it splits into two, one half (sup. posing the resistances equal) passing to each end of the bar, and, by means of the corresponding fork-wires, passing through the movable coils. From the movable coils each half returns along the lower horizontal bar, and together pass out by the lower wire connecting the two main supports. From this the whole current passes tirst through the one fixed coil, and then through the other, and in such a direction as to produce a repulsion between each pair of coils. In the constructing, care is taken that the suspended coils are both made of equal weight, and that when the balance is in equilibrium no torsion is in any of the wires. Small saale-pans are attached to each vertical bar, and a bob for raising or lowering the centre of gravity of the whole is placed on a rod springing at right angles from the middle of one of the horizontal bars. The current strength is estimated by the weight needed to restore the balance to equilibrium when disturbed by the passage of the current. A sliding weight may also be used, as in a steelyard. It will be realily seen that, as in all form; of current-weigher, the weig'its are proportional to the square of the current strength.
Prof. S. P. Thompson described a phenomenon in the electrochemical solution of metals-originally discovered by Plantéwhich occurs when a current is passed between two copper wires immersed in dilute sulphuric acid in a cell. The solution takes place in two stages, the metal first oxidizing, and then the oxide dissolving in the acid. This was projected on the screen, the audience being able to observe that the bubbles evolved when the current was turned on ceased as the current died down, choked by the formation of oxide, but almost immediately recommenced when the oxide began to dissolve. The author has tried other metals and other acids-silver, zinc, and iron showing similar effects in sulphuric acid, but not in nitric, acetic, or hydrochloric acids.

Mr. J. Wilson Swan read a paper on chromic acid as a depolarizer in Bunsen's battery. When chromic acid became an article of commerce at a moderate price, it occurred to the author to see if he could not obtain a substitute for the nitric acid of the Bunsen battery. As the results of his experiments he finds that a solution, of the conposition nitric acid I part, chromic acid 2 parts, sulphuric acid 5 parts, and water 5 parts, gives results equal to that obtained with nitric acid.

Prof. Perry, F.R.S., described a variable standard of self. induction. An instrument like that hitherto used as a variable standard by Prof. Ayrton and the author, was used by Frof. Hughes. It is a fixed coil of wire, inside which a movable coil is placed; the coils are in series one with another. When their planes are parallel there is either a minimum or a maximum coeff:cient. When the movable coil is rotated so that its plane makes various angles with the plane of the fixed coil, a pointer shows on a scale the coefficient for that particular position.

In another paper on a hot twisted strip voltmeter, Prof. Perry described the behaviour of twisted strips subjected to axial pull. A small elongation is accompanied by a great rotation, so that these strips may be employed in measuring instruments such as weighing-machines, aneroid barometers, testing-machines, \&c. For the Ayrton and Perry voltmeter a double twisted strip of platinum silver with its ends insulated is initially in tension inside a tube or frame two-thirds brass and one-third iron, a pointer at the middle of the strip being visible above a dial and capable of a motion of nearly $360^{\circ}$. When the current passes the pointer rotates because of the heating of the strip. By continuous making and breaking of a large current through the strip dnring seventytwo hours all zero and other errors seem to be eliminated. The highest reading of the exhibited instrument was $2 \frac{1}{2}$ volts, so that it is particularly useful in accumulator-work. The author gave the law of transformers generally, and found that a small transformer on the base of the instrument converted it into a voltmeter of any range whatsoever for alternating currents, the readings being independent of the frequency of alternation. The author exhibited twisted strips of carbon made by Messrs. Woodhouse and Rawson, which he intends to use for voltmeters of higher range.

Mr. W. H. Preece, F.R.S., read a paper on the relative effects of steady and alternate curre its on different conductors. Sir W. Thomson, at the Bath meeting of the British Association, stated that alternating currents entered a distance of only about 3 millimetres into the heart of a thick round copper conductor, when the frequency was I 50. This "diffusion law," as he called it, is dependent on the coefficient of self-induction and on the frequency, i.e. on the number of complete alternations of positive and negative currents transmitted per second. As this law has a most important bearing on the commercial value of systems of distribution dependent on alternating currents, it becomes most desirable to study the question practically. The verification of this law is almost beyond the reach of experiment. It occurred to the author, however, that if conductors of different materials are taken, such as iron, copper, lead, and platinoid, of easily measurable lengths and of convenient sectional areas, and if measurable and variable currents, both alternating and direct, approximately similar to those used in practice, are transmitted through them, the question could be studied by observing any difference, if such existed, in the total expenditure of energy in the conductors under these different circumstances. The general conclusion to be drawn from the experiments is that practicaliy no serious error has been made in the form of conductors so much used for alternating current systems, and that nothing cheaper or better has been devised than a simple stranded conductor coated with a suitable insulating coating. The experiments do not solve the question of the distribution of current density through the section of the conductor, but they do show that within the range of practice the total flow of energy is 
the same in copper conductors, whether it be urged by alterate or by steady currents.

Prof. G. Forbes, F.R.S., and Mr. W. H. Preece, F.R.S., in a paper on a new thermometric scale, suggest the joule as the thermal unit instead of the therm or the calorie. $4^{\prime} 2$ joules will raise the temperature of 1 gramme of water at $4^{\circ}$ one degree, hence to raise $I$ gramme of water from freezing-point to boilingpoint requires 420 joules; and it is suggested that the difference of temperature between freezing- and boiling-points should be represented by 420 units of temperature.

Mr. J. T. Bottomley, F. R.S., exhibited some large Leyden jars, broken during the testing of a large Wimshurst machine which was being constructed by Sir Archibald Campbell, Bart., of Blythswood. They were excellent examples of multiple fracture.

Prof. S. P. Thompson, in a paper on sparkless electro-mainets, discussed the various means of suppressing the sparks in the circuits of electro-magnets. The most effective means, he finds, is to surround the core of the magnet with a substantial shield of copper. The author illustrated his method by experiments before the Section.

Mr, W. W. Haldane Gee and Dr. Arthur Harden read a paper on stereometry. This communication relates to the methods used for the determination of the volumes of bodies to which the hydrostatic method is not applicable. The authors have devised a convenient form of instrument, first proposed by Say, and afterwards modified by Le.lie, Kopp, Regnault, and Miller. They have also shown that the following method for ascertaining volumes is very generally applicable, and likely to be of considerable service in physico-chemical researches. The body whose volume is desired is inclosed within a vessel of known volume, and then carbon dioxide (or other dry soluble gas) is passed into it for some time. The gas is then displaced by dry air (or other gas), and the volume of the carbon dioxide driven out is ascertained gravimetrically by absorption in bulbs containing caustic potash solution. By first filling the vessel with dry air and then driving it out with carbon dioxide, the volume of the air, and hence that of the body, may also be ascertained volumetricaly, but with less accuracy. The gravimetric method is especially applicable for accurately ascertaining the density of soluble gases. For this purpose it is far more convenient than the process of direct weighing as used by Regnault.

In a paper on the specific heat of caoutchouc, $\mathrm{Mr}$. W. W. Haldane Gee and Mr. Hubert L. Terry described a number of determinations which had been made of the specific heat of Para india-rubber which had teen masticated, hydraulically compressed, and then cut into sheets from 0.22 millimetre to I 40 millimetre thick. The rubber was alternated with sheets of tinfoil, and heated for two hours in a steam-jacket at $100^{\circ} \mathrm{C}$. A modification of Regnault's method of mixtures was employed to find the specific heat of the hot rubber. Owing to the non-conducting nature of the substance the time of the calorimeter attaining its maximum temperature is as long as ten minutes; hence it has been necessary to apply special formulæ for the correction due to cooling. Those proposed by Pfaundler, Pape, and Schuster have been used, and the results calculated in accordance with them. The mean of the best-conducted experiments gives for the Para rubber the number $0: 486$. The investigation is being extended to allied bodies, especially the different forms of vulcanized rubber and gutta-percha.

Mr. F. T. Trouton read a paper on the temporary thermocurrents in iron. If a portion of an iron wire connected up to a galvanometer be heated red hot, and the heated portion be caused to travel along the wire by moving the flame, a current is produced, which is due to the fact that when iron changes its molecular te at the temperature of recalescence this change does not tal.: place at the same temperature on heating as on cooling, so that when a flame is moved along an iron wire so as to continuously heat it above the temperature of recalescence the junction of the altered with the unaltered metal in front is at a higher temperature than of the junction behind the flame.

Prof. Barrett read a paper on recalescence of iron.

\section{THE CHEMICAL PAPERS AT THE BRITISH} ASSOCIATION.

WING, doubtless, to the numerous chemical industries of the district, many of the papers read in Section B at Newcastle were of special interest to the technical student.
The President's Address on "The Metallurgy of Iron" was followed by the kitcort of the Committee for Investigating the Influence of Silicon on the Properties of Steel. From the results of Mr. Hadfield's experiments, it appears that silicon by itself does not produce a steel that will harden by water-quenching. The brittleness noticed in ordinary so-called silicon steel is due, not to silicon alone, but to the combined presence of the two hardeners, silicon and carbon. Silicon, up to 6 per cent., does not destroy the malleability of iron, nor are the magnetic properties greally affected by increasing percentages of silicon, as is the case with manganese steel.

The Committee for Establishing an International Standard for the Analysis of Iron and Steel reported that they had made goed progress with the work, and hoped before long to have the necessary analyses completed.

Some curious experiments were described by Mr. J. W. Hogg, on the volatilisation of lead oxide and its action upon glass at low temperatures. If some writing is placed upon a glass plate or platirum-foil, using lead oxide as a pigment, if a polished plate of glass be placed over this as closely as jossible and prevented from actual centact by suitable means, upon now heating up to scarcely visible rednes, a distinct reverse of the design will appear upon the upper glass. 'The quantity of lead oxide which will produce this effect is not shown by the most delicate balance.

Photographers were interested in Prof. Liveing's account of a new developer, "Eikonogen," which appears to give greater detail than most of those now in use. The tone of the negative is also excellent. Eikonogen is the sodium salt of amido$\beta$-naphthol- $\beta$-sulphoric acid.

Mr. C. T. Heycocik and Mr. F. H. Neville read a paper on Raoult's method applied to alloys. Alloys of a number of metals with sodium and tin were studied. The "atomic fall" of the freezing-point for aluminium was about half that of most other metals-pointing to twice the present number as the atomic weight of aluminium. Antimony produces a rise in the freezing-point of the alloy, for some unexplained reason. Contrary to Raoult's so-called second law, it was found that the nature of the solvent is of influence; I atomic weight of metal in $r o 0$ atomic weights of sodium not giving the same fall as $I$ in 100 of tin. The method would seem to give a means for correcting and verifying atomic weights; though it does not give much information as to the molecular weight. It was shown that, in accordance with Van 't Hoff's theories on the nature of solution, each metal produces its own lowering of the freezing. point in presence of others.

On the Friday morning, Prof. Dunstan read the Report on the present methods of teaching chemistry.

Prof. Bedson afterwards gave an interesting description of Dr. Netto's process, at work on the Tyne, for the manufacture of aluminium from cryolite. The cryolite is first fused with salt in a reverberatory furnace; then run out into converters in which sodium is gradually added-about five pounds at a time. Sodium fluoride and metallic aluminium are formed. The sodium is obtained by allowing molten caustic soda to flow gradually onto charcoal contained in a cast-iron retort heated to clull redness. The sodium carbonate formed in the reaction sinls to the bottom of the retolt. The greater concentration of the caustic soda thus produced enables the temperature to be kept lower than in the Castner process.

An account was afterwards given, by Mr. J. H. I. Dagger, of the Cowles method for manufacturing aluminium alloys.

On Monday, numerous Reports of Committees were handed in, the most interesting being that read by Dr. Richardson on the action of light on the hydracids. Dr. Richardson has found that, if white light is allowed to act upon water in presence of oxygen, a considerable quantity of hydrogen percxide is productd. This accounts for the fact mentioned in previous Reports, that a mixture of dry oxygen with dry hydrogen chloride, or bromide, is unaffected by light.

Dr. Richardson also exhibited and described a new selfregistering actinometer, based on the fact, discovered by Budde, that chlorine expands in the actinic rays, contracting again in the dark.

Prof. H. B. Dixon gave an account of experiments made by himself and Mr. J. A. Harker, on the explosion of a mixture of hydrogen, chlorine, and oxygen. It was found, in contradiction to previous statements, that steam is produced by the explosion even when chlorine is in excess. It was noted that hydrogen and chlorine, when exploded alone, give a sensible contraction. 